\title{
NF-кB Signaling in the Aging Process
}

\author{
Antero Salminen • Kai Kaarniranta
}

Received: 14 April 2009 / Accepted: 15 April 2009/Published online: 1 May 2009

(C) Springer Science + Business Media, LLC 2009

\begin{abstract}
Introduction The aging process represents a progressive decline in cellular and organism function. Explaining the aging process has given rise to a cornucopia for different theories in which the basic difference has been the question whether aging is genetically regulated or an entropic degeneration process.

Discussion Different screening techniques have revealed that mammalian aging is associated with the activation of $\mathrm{NF}-\mathrm{kB}$ transcription factor system. The NF- $\mathrm{kB}$ system is an ancient host defense system concerned with immune responses and different external and internal dangers, such as oxidative and genotoxic stress. NF- $\mathrm{kB}$ signaling is not only the master regulator of inflammatory responses but can also regulate several homeostatic responses such as apoptosis, autophagy, and tissue atrophy. We will describe how chronic activation of NF-KB signaling has the capacity to induce the senescent phenotype associated with aging.
\end{abstract}

\section{A. Salminen}

Department of Neurology, Institute of Clinical Medicine, University of Kuopio,

P. O. Box 1627, 70211, Kuopio, Finland

\author{
A. Salminen $(\square)$ \\ Department of Neurology, Kuopio University Hospital, \\ P. O. Box 1777, 70211, Kuopio, Finland \\ e-mail: antero.salminen@uku.fi \\ K. Kaarniranta \\ Department of Ophthalmology, Institute of Clinical Medicine, \\ University of Kuopio, \\ P. O. Box 1627, 70211, Kuopio, Finland \\ K. Kaarniranta \\ Department of Ophthalmology, Kuopio University Hospital, \\ P. O. Box 1777, 70211, Kuopio, Finland
}

Interestingly, several longevity genes such as SIRT1, SIRT6, and FoxOs can clearly suppress NF-kB signaling and in this way delay the aging process and extend lifespan. Conclusion It seems that the aging process is an entropic degeneration process driven by NF- $\mathrm{kB}$ signaling. This process can be regulated by a variety of longevity genes along with a plethora of other factors such as genetic polymorphism, immune and dietary aspects, and environmental insults.

Keywords Aging $\cdot$ inflamm-aging $\cdot$ longevity $\cdot \mathrm{NF}-\mathrm{kB}$. SIRT1 · Sirtuins

\section{Introduction}

\section{Aging Theories}

The aging process involves a progressive accumulation of damaged and defective cellular components, which cause a decline in physiological function of tissues and body fitness. This state is called senescence both at the cellular and the organismal levels. Senescence is characterized by a deficiency in maintaining homeostatic processes and increased risk of falling to diseases. Explaining the aging process has been a rich source for different theories based from philosophy to genetics. There are several review articles describing these theories at the general or more focused level [1-3]. The fundamental difference between the theories is the question of whether aging is genetically programmed or not. It has been difficult to discern the difference between the genetically regulated survival processes, which affect the longevity of organism and the aging process itself $[2,4]$. It is even more complicated to 
incorporate the concept of lifespan. Hayflick [4] solved this dilemma shortly "Entropy explains aging, genetic determinism explains longevity".

\section{Genetic Screening of Aging Process}

Progress in molecular biology has made it possible to understand a variety of genetic analyses such as genomewide analysis and expression profiling with microarrays. There has been a great interest to find novel human longevity genes, but very few associations have been characterized at the genome-wide level [5]. Determination genes such as those in developmental biology are rather surprisingly totally lacking. On the contrary, in yeast, worms, and lower animals, the genetic search has been more successful. Several longevity genes such as Sirtuins (Sir2 homologs) and FoxOs (daf-16) have been revealed [6, 7] but it seems that they are survival genes rather than the determinants of the aging process. Even more numerous genes have been uncovered in functional genomics assays, i.e., expression profiling studies [8,9]. A huge number of genes seem to be differentially regulated during the aging process, and a great many articles have been published. In particular, studies on human progeroid syndromes have been interesting [8] since hopefully they can reveal the functional pathways underlying the entropic processes in aging, as defined by Hayflick [4].

Recently, de Magalhaes et al. [9] performed a metaanalysis of age-related expression profiles of 27 datasets from mice, rats, and humans. The most common age-related genetic signature involved the overexpression of inflammation and immune response genes and also the genes linked to the function of lysosomal system. This indicates that the entropy related to aging process activates the innate immunity system. This process is called inflamm-aging (see below) [3, 10].

\section{NF-кB Activation: A Hallmark of the Aging Process}

\section{Early Observations}

Expression profiling of age-related changes reveals only changes in mRNA levels but this does not reflect changes in translational levels and post-translational modifications. Many of the developmental determination genes are transcription factors, which can regulate transcription by binding to specific DNA sites on the promoter regions of target genes. Screening of age-related changes in transcription factor binding activities in nuclear extracts can reveal several functional aspects from genetic regulation, such as changes in protein levels, nuclear translocation, and modifications, which all can affect the complex formation and the DNA-binding efficiency.
Fifteen years ago, we screened with the electrophoretic mobility shift assay (EMSA) technique a large number of transcription factor binding activities using commercially available double-stranded DNA-binding sites in the nuclear extracts of several tissues from young and old rodents. Surprisingly, we observed that the DNA-binding activity of the NF- $\kappa B$ complex was significantly increased in all rat and mouse tissues that we studied [11-13]. The age-related change was the most prominent in liver but also cardiac muscle and brain samples showed clearly elevated levels of NF- $\kappa \mathrm{B}$ binding activity. The increase was specific since the DNA-binding activity of several other factors was unaffected or down-regulated, such as AP-1 and Sp1 factors in liver [11] and cardiac muscle [12]. Supershift assays were used to verify that the major complex contained the NF-kB components [12, 14]. Interestingly, the EMSA assays consistently demonstrated that the DNA-binding pattern of NF- $\kappa B$ complexes was similar in young and old animals but only the density of binding complexes increased. We also used the ultraviolet crosslinking assay to verify that the DNA-binding component was about $50 \mathrm{kDa}$ [12], like NF$\mathrm{kB}$ components (see below).

We also demonstrated that the protein levels of NF- $k \mathrm{~B}$ components p52 and p65 but not that of p50 were clearly higher in the nuclear extracts of old rodents compared to those of young ones $[11,12,14]$. Age-related changes were not recorded in the cytoplasmic levels of these NF-kB protein components. Moreover, aging did not affect the protein levels of $\mathrm{I}_{\kappa} \mathrm{B}$ inhibitors and the activating kinases of the NF- $\kappa$ B system, IKK $\alpha / \beta$ (IkB kinase $\alpha$ and $\beta$ ) and NIK (NF-KB -inducing kinase) [11, 14]. Furthermore, the expression levels of p52 and p65 mRNAs and those of $\mathrm{I} \kappa \mathrm{B} \alpha$ and $\beta$ mRNAs were also unaffected during aging [14]. There seems to be two alternative possibilities, either the retention of $\mathrm{NF}-\mathrm{kB}$ proteins into the nuclei increases with aging or immune cells with higher normal levels of NF- $\kappa B$ components accumulate in the tissues of old rodents. The latter possibility seems unlikely since we did not observe any age-related changes in the levels of mRNA expression. Furthermore, microarray profiling studies have not detected any age-related changes in the expression levels of NF- $\mathrm{kB}$ or I $\mathrm{kB}$ component mRNAs (see below).

This age-related constitutive activation of NF- $k B$ system has been verified later by several other research groups, which have studied the changes in NF-kB system, using mostly EMSA technique [15-18]. The observations of Spencer et al. [16] are especially interesting, which demonstrated that the DNA-binding activity of NF- $\mathrm{BB}$ complex is clearly increased with aging in the major lymphoid tissues and cells, such as spleen, bone marrow, mesenteric and peripheral lymph nodes, and Peyer's patches. They also demonstrated that $\mathrm{T}$ and B lymphocytes and the macrophage population isolated from the spleen of 
old mice exhibited a constitutive activation of the NF- $\kappa B$ system compared to that of mature adult mice. Moreover, Spencer et al. [16] and Poynter and Daynes [17] have demonstrated that dietary therapies with antioxidants and PPAR- $\alpha$ agonist can down-regulate the age-related increase in the DNA-binding activity of the NF- $\mathrm{kB}$ complex, as well as the increased expression of IL-6 and IL-12 cytokines. These observations imply that oxidative stress has a major role in the constitutive activation of the NF- $\mathrm{KB}$ system in tissues during aging. Giardina and Hubbard [19] and Gosselin and Abbadie [20] have reviewed the age-related functions of redox-dependent NF- $\mathrm{KB}$ system.

\section{Motif Module Mapping}

The age-related increase in the DNA-binding activity of NF- $\mathrm{BB}$ complex in nuclear extracts of young and old rodents (see above) suggests that the NF- $k B$ system is constitutively activated with aging. Furthermore, the metaanalysis of expression profile showed that the inflammatory and immune response genes are overexpressed during aging although the expression levels of NF- $\mathrm{KB}$ components are unaffected [9]. This also implies that NF- $\kappa B$ activity is increased with aging since $\mathrm{NF}-\mathrm{KB}$ signaling is the major regulator of immune responses (see below). Adler et al. [21] have provided further evidence on the importance of NF- $\mathrm{BB}$ signaling in the age-related expression profile by motif module mapping technique. They used a bioinformatics approach to identify cis-regulatory motifs of differentially expressed genes to reveal transcription factor binding sites, which are associated with aging changes in gene expression profiles. Interestingly, they demonstrated that the NF-KB motif was the most strongly associated module with aging in multiple human and mouse tissues. Moreover, NF- $\mathrm{KB}$ motif was among the top modules in the cells from Hutchinson-Guilford progeria, a premature aging syndrome [21].

Adler et al. [21] also verified the earlier DNA-binding studies (see above) showing that the DNA-binding activity of NF-kB was increased with aging in mouse skin, heart, kidney, liver, and spleen. They demonstrated convincingly that the inducible genetic blockade of NF- $\mathrm{kB}$ in the skin of aged mice can revert the tissue characteristics and gene expression profiles to those of young mice. This may be the first successful rejuvenation experiment.

\section{NF-кB Pathway: Sensor of Stress and Immune Insults}

The NF- $\mathrm{KB}$ transcription factor system was discovered over 20 years ago by Sen and Baltimore [22]. Subsequently, the structural and functional properties of the NF-KB system have been intensively studied, and recently, several exhaus- tive review articles have been published [23-26]. In the center of NF- $\mathrm{KB}$ signaling, there are the proteins of three families: (1) the NF-KB/Rel DNA-binding complexes, which contain the Rel family components, RelA/p65, c-Rel, and RelB, as well as the NF- $\mathrm{BB}$ components p50 (p105) and p52 (p100); (2) the inhibitory IKB components $\alpha, \beta, \gamma, \varepsilon$, and Bcl-3; and (3) the IKK kinase complex proteins $\mathrm{IKK} \alpha, \operatorname{IKK} \beta$, and the regulatory NEMO protein, which can trigger the NF- $\mathrm{B}$ signaling. In non-stimulated cells, the NF-KB complexes are located in cytoplasm because they are bound to the inhibitory I $\kappa \mathrm{B}$ proteins. Stimulation, either external or internal, activates several protein kinases, which can phosphorylate I $\mathrm{B}$ proteins that are subsequently ubiquitinated and degraded via proteasomes. After their release from I $\mathrm{B}$ proteins, NF- $\kappa \mathrm{B}$ complexes can translocate to nuclei and activate the transcription of a number of specific target genes, especially those of inflammatory genes observed to be upregulated during aging [9].

IKKs (I $\kappa$ B kinases $\alpha$ and $\beta$ ) are the major protein kinases activating NF- $\mathrm{KB}$ complexes via canonical or noncanonical pathways in cytoplasm although IKKindependent pathways also exist [24-26]. NEMO, an essential NF- $\mathrm{kB}$ modulator and regulatory subunit of IKK complex, regulates the activation of the IKK kinase complex [27]. NEMO protein is involved in several signaling cascades, e.g., in the case of genotoxic stress [28]. DNA damage is the causative factor in several progeroid syndromes, such as Werner syndrome and Hutchinson-Gilford syndrome. We have recently reviewed the details of the NEMO shuttle and speculated that the NEMO shuttle may be activated in progeroid syndromes that can subsequently evoke a premature aging phenotype by activating the NF- $\mathrm{KB}$ system [29].

$\mathrm{NF}-\mathrm{KB}$ system is a cytoplasmic sensor in particular to immune attacks but also to a wide array of external and internal danger signals such as oxidative stress, hypoxia, and genotoxic stress (Fig. 1). Sometime ago, it was observed that oxidative stress is a sensitive inducer of NF$\mathrm{kB}$ system [30]. Oxidative stress triggered by free radicals is a classical mechanism, which is associated with the aging process and can cause degenerative processes [31, 32]. Recently, it was demonstrated that the activation occurs via the classical IKK-dependent pathway [33]. Interestingly, reactive oxygen species (ROS) are also involved in the NF$\kappa \mathrm{B}$ signaling induced by pro-inflammatory cytokines, such as IL-1ß and TNF- $\alpha$ [33]. Wuerzberger-Davis et al. [34] have demonstrated that ROS can also activate the NEMO shuttle and promote the activation of the IKK complex and NF-kB signaling. Chronic UVB (ultraviolet radiation) exposure, e.g., by sunlight, induces oxidative stress in the skin and accelerates the aging process, called photoaging [35]. Acute exposure to UVB triggers NF- $\mathrm{BB}$ system in 


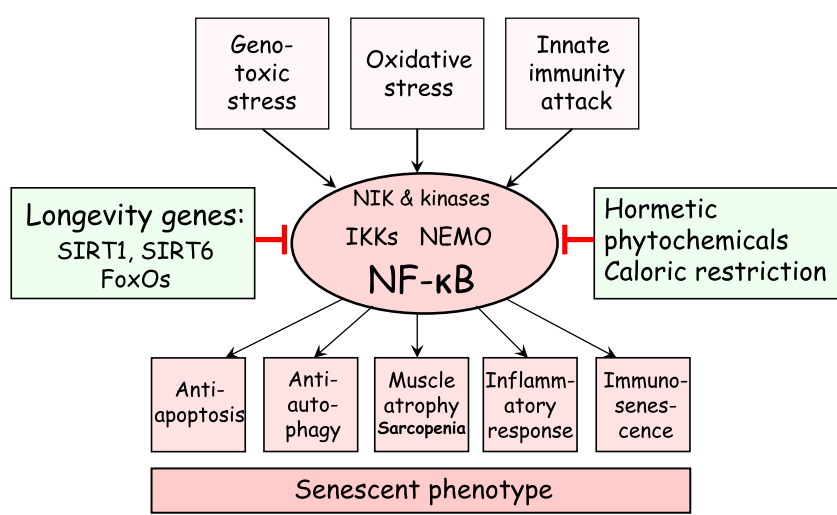

Fig. 1 Schematic illustration on the entropic aging process driven by NF-KB signaling. The senescence pathway can be regulated by longevity genes along with dietary aspects such as hormetic phytochemicals and caloric restriction

keratinocytes and skin fibroblasts. NF- $\mathrm{kB}$ inhibitors can suppress the changes evoked by UV light in skin, which supports the role of NF- $\mathrm{kB}$ system in the photoaging process [36].

NF- $\mathrm{KB}$ pathway is the major transcription factor, which mediates the immune signals of the invaders and the inducer of host defense [26, 37] (Fig. 1). Innate immunity is the most ancient form of host defense in multicellular organisms, and the NF- $\mathrm{kB}$ system has probably developed simultaneously with the signaling mechanisms of cellular defense system [37-39]. There are several pattern recognition receptors (PRRs) in organisms to protect against invading pathogens, so-called pathogen-associated molecular patterns, or receptors recognizing the damage-associated molecular patterns in self [40]. Toll-like receptors (TLRs) represent the major and a highly conserved part of host defense receptor system in mammals [41]. Signaling pathways of TLRs are well known and has been frequently reviewed [26, 37]. Briefly, the major TLR pathways are linked to NF- $\mathrm{KB}$ system via different adapter proteins and protein kinases. The IKKß kinase is the major regulator in NF-kB-mediated inflammatory signaling. Several cytokine receptors are also linked to NF- $\mathrm{KB}$ signaling to potentiate the inflammatory responses. There are several other PPRs in mammalian cells, such as receptor for advanced glycation endproducts, NOD-like receptors, and retinoic acid inducible genes. Interestingly, several innate immunity PRRs are present also in non-specialized immune cells. We have recently reviewed the innate immunity defense reactions, PRRs involved, and signaling pathways in Alzheimer's disease [42].

Immunosenescence is a well-characterized age-related decline in the function of the immune system [43]. The major changes in this phenomenon involve thymic involution and alterations in $\mathrm{T}$ cell subsets, including the exhaustion of CD45RA+ naive T cells. NF- $\mathrm{kB}$ system has important functions in the regulation of both innate immunity (see above) and also adaptive immunity [44]. $\mathrm{NF}-\mathrm{KB}$ signaling is involved in $\mathrm{T}$ cell development, activation, and proliferation [44, 45]. Trebilcock and Ponnappan [46] demonstrated that the induction efficiency of NF- $\mathrm{kB}$ system to TNF- $\alpha$ exposure was significantly lower in different subsets of $\mathrm{T}$ cells obtained from the elderly than cells from young people. The age-related attenuation of NF- $\mathrm{KB}$ signaling response in $\mathrm{T}$ cells is reminiscent of our findings in replicatively senesced skin fibroblasts after UVB exposure [47]. Huang et al. [48] demonstrated also a diminished level of NF-KB activation in mouse-aged splenic CD4 T cells but interestingly, NF-kB inhibitors were able to correct the alterations of immunosenescence.

\section{Longevity Genes Suppress NF-KB Signaling}

\section{Sirtuins}

The budding yeast model of aging has been a popular model in aging research and provided several insights into the mechanisms underpinning senescence. Sinclair and Guarente [49] demonstrated that the recombination in yeast rDNA locus and the subsequent accumulation of extrachromosomal rDNA circles in senescent cells induce the aging phenotype of budding yeast. Later studies elucidated that the promotion of yeast longevity was induced by Sir2 (silent information regulator 2) [50]. Sir2 protein is a $\mathrm{NAD}^{+}$-dependent protein deacetylase, and it has several homologs in different species, e.g., seven SIRTs in human [51]. Sir2 types of enzymes form the class III histone deacetylase group and they are called Sirtuins [51]. Recent studies have revealed that Sirtuins can target a wide array of acetylated proteins, and they are involved in several cellular functions such as metabolic regulation and maintenance of cell survival $[51,52]$. Furthermore, they are also linked to mammalian aging and several age-related diseases such as diabetes, metabolic syndrome, and neurodegenerative diseases [51-53].

SIRT1 is the most extensively studied of the mammalian Sirtuins. For example, it has a central role in the regulation of cellular signaling related to cellular metabolism and survival [51, 54]. Interestingly, Yeung et al. [55] demonstrated that SIRT1 can physically interact with the p65/ RelA protein in the NF-KB complex, specifically to deacetylate the lysine-310 of p65 protein. The cleavage and removal of the acetyl group inhibit the transactivation efficiency of NF-KB-dependent complex since acetylated lysine-310 is a powerful promoter of the transactivation of the NF-KB complex. These observations confirm that SIRT1 is a potent intracellular inhibitor of NF- $\mathrm{KB}$ transcription [55] (Fig. 1). The role of SIRT1 as a suppressor of inflammatory reactions has been demonstrated recently [56, 
57]. For instance, Kwon et al. [57] showed that HIV-1 Tat protein can bind to the deacetylase domain in SIRT1 protein and thereby inhibit the SIRT1-mediated deacetylation of the $\mathrm{p} 65$ protein. This inhibition potentiates the transactivation efficiency of NF- $\mathrm{KB}$ factor, which evokes immune activation involving $\mathrm{T}$ cell hyperactivation and finally leads to the depletion of CD4+ T cells.

SIRT6 is another Sirtuin-based longevity factor, which seems to regulate DNA repair, metabolism, and aging [58]. Mice lacking SIRT6 protein can develop a phenotype displaying degenerative changes, which mimic accelerated aging [59]. Recently, Kawahara et al. [60] demonstrated that SIRT6 interacts with p65/RelA component and is recruited to the promoters of certain NF- $\mathrm{KB}$ target genes. SIRT6 can deacetylate histone H3 lysine- 9 on these promoters and thereby destabilize the binding of NF- $\mathrm{KB}$ complex to DNA, which represses the expression of the NF-kB-regulated genes (Fig. 1). Interestingly, they also demonstrated that SIRT6 depletion can elevate apoptotic resistance by inducing the expression of antiapoptotic genes and that may increase senescence of primary keratinocytes [60]. The motif module mapping of the expression profiles demonstrated that the NF-kB-driven genes were overexpressed in SIRT6 knockout mice although certain specificity was present [60]. These results indicate that (1) SIRT6 can inhibit a subset of NF-kB target genes by modifying the chromatin structure at their promoters and (2) hyperactive NF-KB signaling can induce premature aging phenotype.

\section{FoxOs}

Mammalian FoxO transcription factors are homologs to the DAF-16 protein of Caenorhabditis elegans. Several longevity genes have been cloned using a diapause model, i.e., dauer larva model, where the development of $C$. elegans is arrested due to the presence of harsh environmental conditions [61]. DAF-16 seems to be a key regulator of longevity in C. elegans [61, 62]. Non-functional mutations in DAF-2 (insulin/IGF-1 receptor) and AGE-1 (PI-3 K), upstream regulators of DAF16, can also induce the formation of the dauer stage in the larva [62]. Inhibition of DAF-2 pathway by mutations induces the translocation of DAF-16 factor from the cytoplasm to the nucleus. The activation of several target genes can induce the survival response and in that way also extend the lifespan. The DAF-2/DAF-16 pathway is analogous to the mammalian IGF-1/PI-3 K/FoxO pathway. Numerous target genes to DAF-16/FoxO have been cloned, and many of them seem to regulate stress resistance, cell cycle, metabolic balance, as well as longevity [63].

FoxO signaling pathway has an important role in the regulation of mammalian immune system homeostasis [64,
65]. Lin et al. [66] demonstrated that FoxO3a knockout mice displayed a lymphoproliferative disease, which was associated with inflammatory responses in several tissues. Interestingly, they demonstrated that this multisystem inflammation could be linked to the activation of NF- $\mathrm{KB}$ signaling, which was induced by the lack of FoxO3ainduced inhibition of NF-KB (Fig. 1). Lin et al. [66] also demonstrated that the increase in FoxO3a expression can inhibit the TNF $\alpha$-induced activation of the NF- $\mathrm{kB}$ system in different cell types. FoxO3a can promote apoptosis by suppressing NF- $\mathrm{KB}$ system and activating c-Jun N-terminal kinase (JNK) signaling after TNF $\alpha$ exposure in endothelial cells [67].

It seems that the longevity factors can suppress the NF$\kappa B$-driven inflammatory and aging process (Fig. 1), i.e., the entropic process described by Hayflick [4]. SIRT1 inhibits NF-KB activation and inflammatory responses (see above) but it can also induce the FoxO/DAF-16 signaling [68], which might further potentiate the inhibition of the NF$\mathrm{KB}$ system. These signaling interactions provide an interesting basis for elucidating the function of longevity genes, which can extend lifespan by inhibiting the NF-kB-driven inflammatory and degenerative processes $[3,69]$.

\section{NF-KB Signaling: Inducer of Senescent Phenotype}

Several different approaches have demonstrated that the activation of NF- $\mathrm{KB}$ signaling is associated with the aging process (see above). Furthermore, it seems that the activation is not the consequence of aging but rather a cause of the degenerative processes (Fig. 1). One interesting question arises: How can the NF- $\mathrm{KB}$ signaling carry out this entropic process? It is known well that NF-KB is also involved in developmental processes, e.g., with the name Toll-Dorsal pathway it induces the dorsal-ventral patterning of Drosophila embryo [70]. The NF-kB system is one of the pleiotrophic factors, which can have diverse functions during lifespan.

The main function of NF- $\mathrm{KB}$ system is to organize the host defense against both immune attacks and self-damage in the organism. The inflammatory response can be either beneficial leading to repair of tissues or degenerative [71, 72]. Chronic inflammation in tissues is harmful in many ways: (1) increasing oxidative stress and lipid peroxidation, (2) secreting metalloproteases and inducing matrix degeneration, and (3) secreting cytokines and toxins, which can cause a multitude of cellular dysfunctions. Furthermore, the number of tissue macrophages increases, which still aggravates degenerative processes. A chronic inflammatory reaction can induce tissue atrophy, either cachexia or sarcopenia [73] (Fig. 1). 
Cachexia is associated with cancer and inflammatory diseases, and it can appear in several tissues, mostly in skeletal muscles [74], whereas sarcopenia denotes the agerelated muscle atrophy [73]. Recent studies have convincingly demonstrated that the NF- $\mathrm{KB}$ pathway is the major signaling mechanism, which can induce muscle atrophy $[75,76]$. Cachexia is caused by TNF- $\alpha$, which activates the NF-kB system in many tissues, e.g., in skeletal muscle, and causes atrophy [75]. Several other pro-inflammatory cytokines such as TWEAK and IL- $1 \beta$ can also induce muscle atrophy. NF- $\mathrm{KB}$ signaling triggers the expression of MuRF1, a muscle-specific E3 ubiquitin ligase, and subsequently, the enhanced proteasomal degradation evokes muscle atrophy [76]. Another E3 ubiquitin ligase, atrogin-1, can also enhance muscle atrophy but it is under the regulation of the FoxO pathway [77].

The aging process involves a progressive accumulation of cellular damage and protein aggregates in cells, in particular in post-mitotic cells. Waste theories, i.e., "garbagecan hypotheses", are common and support the entropy statement $[1,4]$. The senescent phenotype indicates that there are age-related deficiencies in the autophagy and apoptosis. Recent studies have demonstrated that both of these vital processes decline during aging [78-81]. Apoptosis is a double-edged sword since the increased antiapoptotic potential may lead to cancer in cells able to undergo mitosis. On the other side of the equation, the resistance to apoptosis in cells, which are not prone to mitosis, prevents the natural cleaning and renewal of cells in many tissues, e.g., in skin and vascular endothelium. Replicative senescence, for instance, is associated with an increase in resistance to apoptosis [78]. Interestingly, NF- $\mathrm{KB}$ signaling is a key player in apoptotic resistance [82] (Fig. 1). NF-KB signaling can, for instance, activate the expression of inhibitors of apoptosis, e.g., Bcl-xL, IAP1, IAP2. Furthermore, NF-kB signaling also represses the apoptotic signaling by inhibiting the function of JNK, a well-known mediator of apoptotic signals [83].

Autophagy is an intracellular cleansing process, which mediates protein and organelle degradation via the lysosomal pathway. Recent studies have demonstrated that autophagic degradation declines during aging, which results in the accumulation of dysfunctional proteins and organelles such as mitochondria in senescent cells [84, 85]. Lipofuscin, an aging pigment, is a hallmark characteristic of the aging process in post-mitotic cells. Several studies have recently indicated that NF- $\mathrm{KB}$ signaling is a potent inhibitor of autophagocytosis [80]. Dan and Baldwin [86] have shown that both IKK $\alpha$ and IKK $\beta$ are involved in the activation of the mTOR/Raptor complex, a well-known inhibitor of autophagy, in response to TNF $\alpha$ and insulin exposure. They also demonstrated that IKK $\beta$, activated by inflammatory signals, can suppress the tuberous sclerosis complex (TSC), a repressor of mTOR/Raptor, and in that way, it can activate mTOR kinase and inhibit autophagocytosis. Lee et al. [87] also observed that $\mathrm{TNF} \alpha$-activated IKK $\beta$ can suppress TSC1 and hence trigger the mTOR pathway. These observations indicate that chronic inflammation and NF- $\mathrm{kB}$ signaling are potent inhibitors of autophagy during aging (Fig. 1). Furthermore, several studies have indicated that two longevity factors SIRT1 and FoxO3, inhibitors of NF-kB signaling (see above), are powerful enhancers of autophagocytosis [80, 88]. It seems that the deficiency in the cleansing capacity leads to the appearance of senescent phenotype (Fig. 1).

\section{Therapeutics Against Aging Process?}

Traditional medicine offers a cornucopia of therapeutic compounds said to be efficacious against the aging process and common age-related diseases. However, their clinical relevance needs still to be established. Interestingly, most of these plant-derived compounds are well-known natural inhibitors of NF-KB signaling [89, 90]. A plethora of studies indicate that they have antiinflammatory and anticancer properties, which will agree with their function as NF- $\mathrm{kB}$ inhibitors. Most of the compounds are flavonoids or terpenoids, which are ingredients of plant products and traditional remedies [89-91]. It has been known for a long time that phytochemicals can cause a low level of cellular stress, which can induce an adaptive stress response in cells or organisms. This adaptation subsequently protects cells against more intense stress and insults. This phenomenon has been called hormesis [92, 93]. Stress resistance in general correlates to the maximal lifespan of organisms, and in that way, hormetic phytochemicals could increase longevity.

Resveratrol, curcumin, and catechines are typical hormetic phytochemicals [92]. Interestingly, resveratrol can activate SIRT1 deacetylase [51] and in that way inhibit NF- $\mathrm{kB}$ signaling (Fig. 1). However, resveratrol has a plethora of other targets and exerts many effects in cells, i.e., it may have antiinflammatory and cardioprotective properties [94]. The NF-KB signaling pathway has numerous interactions with signaling networks, and hence, the inhibition of the whole NF- $\mathrm{kB}$ system may be harmful. Thalidomide is an alarming example of an NF- $\mathrm{KB}$ inhibitor since it can cause severe birth defects [95]. In particular, the inhibition of IKK $\alpha$ can be dangerous during pregnancy since IKK $\alpha$ kinase regulates mammalian development, and its deficiency can induce abnormalities, e.g., in limb organogenesis. The NF- $\mathrm{KB}$ signaling pathway is a promising drug target but it will be essential to develop specific inhibitors to the distinct branches of NF- $\mathrm{KB}$ signaling cascades. 
Caloric restriction (CR) is the only treatment which is known to extend lifespan in all organisms ranging from yeast to mammals. This topic received a new facet when it was demonstrated that $\mathrm{CR}$ can increase the expression of SIRT1 and the cellular level of $\mathrm{NAD}^{+}$, an activator of SIRT1 [96]. The activation of SIRT1 and the subsequent inhibition of NF- $\mathrm{KB}$ signaling could also induce the resistance to inflammation that occurs during CR [97] (Fig. 1). Microarray studies have revealed that $\mathrm{CR}$ can prevent the appearance of the age-related pro-inflammatory gene expression profile [98]. The SIRT1-mediated inhibition of NF-KB signaling could also explain the protective effects of CR against age-related metabolic diseases such as the metabolic syndrome [52].

Acknowledgments This study was financially supported by grants from the Academy of Finland and the University of Kuopio, Finland. The authors thank Dr. Ewen MacDonald for checking the language of the manuscript.

\section{References}

1. Troen BR. The biology of aging. Mt Sinai J Med. 2003;70:3-22.

2. Finch CE, Ruvkun G. The genetics of aging. Annu Rev Genomics Hum Genet. 2001;2:435-62. doi:10.1146/annurev.genom.2.1.435.

3. Salminen A, Huuskonen J, Ojala J, Kauppinen A, Kaarniranta K, Suuronen T. Activation of innate immunity system during aging: $\mathrm{NF}-\mathrm{KB}$ signaling is the culprit of inflamm-aging. Ageing Res Rev. 2008;7:83-105. doi:10.1016/j.arr.2007.09.002.

4. Hayflick L. Entropy explains aging, genetic determinism explains longevity, and undefined terminology explains misunderstanding both. PLoS Genet. 2007;3:e220. doi:10.1371/journal. pgen.0030220.

5. Capri M, Salvioli S, Sevini F, Valensin S, Celani L, Monti D, et al. The genetics of human longevity. Ann N Y Acad Sci. 2006;1067:252-63. doi:10.1196/annals.1354.033.

6. Warner HR. Longevity genes: from primitive organisms to humans. Mech Ageing Dev. 2005;126:235-42. doi:10.1016/j. mad.2004.08.015.

7. Smith ED, Kennedy BK, Kaeberlein M. Genome-wide identification of conserved longevity genes in yeast and worms. Mech Ageing Dev. 2007;128:106-11. doi:10.1016/j.mad.2006.11.017.

8. Vijg J, Calder RB. Transcript of aging. Trends Genet. 2004;20:221-4. doi:10.1016/j.tig.2004.04.007.

9. De Magalhaes JP, Curado J, Church GM. Meta-analysis of agerelated gene expression profiles identifies common signatures of aging. Bioinformatics. 2009;25:875-81. doi:10.1093/bioinformatics/ btp073.

10. Franceschi C, Valesin S, Bonafe M, Paolisso G, Yashin AI, Monti $\mathrm{D}$, et al. The network and the remodeling theories of aging: historical background and new perspectives. Exp Gerontol. 2000;35:879-96. doi:10.1016/S0531-5565(00)00172-8.

11. Helenius M, Hanninen M, Lehtinen SK, Salminen A. Changes associated with aging and replicative senescence in the regulation of transcription factor nuclear factor- $\mathrm{kB}$. Biochem J. 1996;318:603-8.

12. Helenius M, Hanninen M, Lehtinen SK, Salminen A. Aging-induced up-regulation of nuclear binding activities of oxidative stress responsive NF- $\mathrm{KB}$ transcription factor in mouse cardiac muscle. J Mol Cell Cardiol. 1996;28:487-98. doi:10.1006/jmcc.1996.0045.
13. Korhonen P, Helenius M, Salminen A. Age-related changes in the regulation of transcription factor NF-kB in rat brain. Neurosci Lett. 1997;225:61-4. doi:10.1016/S0304-3940(97) 00190-0.

14. Helenius M, Kyrylenko S, Vehvilainen P, Salminen A. Characterization of aging-associated up-regulation of constitutive nuclear factor- $\mathrm{kB}$ binding activity. Antioxid Redox Signal. 2001;3:14756. doi:10.1089/152308601750100669.

15. Roy AK, Vellanoweth RL, Chen S, Supakar PC, Jung MH, Song CS, et al. The evolutionary tangle of aging, sex, and reproduction and an experimental approach to its molecular dissection. Exp Gerontol. 1996;31:83-94. doi:10.1016/05315565(95)00020-8.

16. Spencer NFL, Poynter ME, Im SY, Daynes RA. Constitutive activation of NF- $\mathrm{KB}$ in an animal model of aging. Int Immunol. 1997;9:1581-8. doi:10.1093/intimm/9.10.1581.

17. Poynter ME, Daynes RA. Peroxisome proliferator-activated receptor alpha activation modulates cellular redox status, represses nuclear factor- $\mathrm{kB}$ signaling, and reduces inflammatory cytokine production in aging. J Biol Chem. 1998;273:32833-41. doi:10.1074/jbc.273.49.32833.

18. Kim HJ, Kim KW, Yu BP, Chung HY. The effect of age on cyclooxygenase-2 gene expression: NF- $\mathrm{KB}$ activation and $\mathrm{I} \kappa \mathrm{B} \alpha$ degradation. Free Radic Biol Med. 2000;28:683-92. doi:10.1016/ S0891-5849(99)00274-9.

19. Giardina C, Hubbard AK. Growing old with nuclear factor-kB. Cell Stress Chaperones. 2002;7:207-12. doi:10.1379/1466-1268 (2002)007<0207:GOWNFB>2.0.CO;2.

20. Gosselin K, Abbadie C. Involvement of Rel/NF-kB transcription factors in senescence. Exp Gerontol. 2003;38:1271-83. doi:10.1016/j.exger.2003.09.007.

21. Adler AS, Sinha S, Kawahara TLA, Zhang JY, Segal E, Chang HY. Motif module map reveals enforcement of aging by continual NF- $\mathrm{kB}$ activity. Genes Dev. 2007;21:3244-57. doi:10.1101/gad.1588507.

22. Sen R, Baltimore D. Multiple nuclear factors interact with the immunoglobulin enhancer sequences. Cell. 1986;46:705-16. doi:10.1016/0092-8674(86)90346-6.

23. Chen LF, Greene W. Shaping the nuclear action of NF-kB. Nat Rev Mol Cell Biol. 2004;5:392-401. doi:10.1038/nrm1368.

24. Hayden MS, Ghosh S. Signaling to NF-kB. Genes Dev. 2004;18:2195-224. doi:10.1101/gad.1228704.

25. Scheidereit C. I KB kinase complexes: gateways to NF-kB activation and transcription. Oncogene. 2006;25:6685-705. doi:10.1038/sj.onc.1209934.

26. Perkins ND. Integrating cell-signalling pathways with NF-kB and IKK function. Nat Rev Mol Cell Biol. 2007;8:49-62. doi:10.1038/ nrm2083.

27. Sebban H, Yamaoka S, Courtois G. Posttranslational modifications of NEMO and its partners in NF-kappaB signaling. Trends Cell Biol. 2006;16:569-77. doi:10.1016/j.tcb.2006.09.004.

28. Janssens S, Tschopp J. Signals from within: the DNA-damageinduced NF-kB response. Cell Death Differ. 2006;13:773-84. doi:10.1038/sj.cdd.4401843.

29. Salminen A, Suuronen T, Huuskonen J, Kaarniranta K. NEMO shuttle: a link between DNA damage and NF- $\mathrm{KB}$ activation in progeroid syndromes? Biochem Biophys Res Commun. 2008;367:715-8. doi:10.1016/j.bbrc.2007.11.189.

30. Schreck R, Albermann K, Baeuerle PA. Nuclear factor $\kappa B$ : an oxidative stress-responsive transcription factor of eukaryotic cells (a review). Free Radic Res Commun. 1992;17:221-37. doi:10.3109/10715769209079515.

31. Harman D. Free radical theory of aging. Mutat Res. 1992;275:257-66.

32. Martin GM, Austad SN, Johnson TE. Genetic analysis of ageing: role of oxidative damage and environmental stresses. Nat Genet. 1996;13:25-34. doi:10.1038/ng0596-25. 
33. Gloire G, Legrand-Poels S, Piette JNF. $\mathrm{kB}$ activation by reactive oxygen species: fifteen years later. Biochem Pharmacol. 2006;72:1493-505. doi:10.1016/j.bcp.2006.04.011.

34. Wuerzberger-Davis SM, Nakamura Y, Seufzer BJ, Miyamoto SNF. $\mathrm{KB}$ activation by combinations of NEMO SUMOylation and ATM activation stresses in the absence of DNA damage. Oncogene. 2007;26:641-51. doi:10.1038/sj.onc.1209815.

35. Rabe JH, Mamelak AJ, McElgunn PJS, Morison WL, Sauder DN. Photoaging: mechanisms and repair. J Am Acad Dermatol. 2006;55:1-19. doi:10.1016/j.jaad.2005.05.010.

36. Tanaka K, Hasegawa J, Asamitsu K, Okamoto T. Prevention of the ultraviolet B-mediated skin photoaging by a nuclear factor $\mathrm{KB}$ inhibitor, parthenolide. J Pharmacol Exp Ther. 2005;315:624-30. doi:10.1124/jpet.105.088674.

37. Trinchieri G, Sher A. Cooperation of Toll-like receptor signals in innate immune defence. Nat Rev Immunol. 2007;7:179-90. doi:10.1038/nri2038.

38. Danilova N. The evolution of immune mechanisms. J Exp Zool. 2006;306B:496-520.

39. Friedman R, Hughes AL. Molecular evolution of the NF-kappaB signaling system. Immunogenet. 2002;53:964-74. doi:10.1007/ s00251-001-0399-3.

40. Bianchi ME. DAMPs, PAMPs and alarmins: all we need to know about danger. J Leukoc Biol. 2007;81:1-5. doi:10.1189/ jlb.0306164.

41. Medzhitov R, Janeway C Jr. Innate immune recognition: mechanisms and pathways. Immunol Rev. 2000;173:89-97. doi:10.1034/j.1600-065X.2000.917309.x.

42. Salminen A, Ojala J, Kauppinen A, Kaarniranta K, Suuronen T. Inflammation in Alzheimer's disease. Amyloid- $\beta$ oligomers trigger innate immunity defence via pattern recognition receptors. Prog Neurobiol. 2009;87:181-94. doi:10.1016/j.pneurobio.2009.01.001.

43. Larbi A, Franceschi C, Mazzatti D, Solana R, Wikby A, Pawelek G. Aging of the immune system as a prognostic factor for human longevity. Physiology (Bethesda). 2008;23:64-74. doi:10.1152/ physiol.00040.2007.

44. Caamano J, Hunter CANF. אB family of transcription factors: central regulators of innate and adaptive immune functions. Clin Microbiol Rev. 2002;15:414-29. doi:10.1128/CMR.15.3.414-429.2002.

45. Liang Y, Zhou Y, Shen P. NF-kB and its regulation on the immune system. Cell Mol Immunol. 2004;5:343-50.

46. Trebilcock GU, Ponnappan U. Nuclear factor $\mathrm{kB}$ induction in $\mathrm{CD} 45 \mathrm{RO}+$ and CD45RA $+\mathrm{T}$ cell subsets during aging. Mech Ageing Dev. 1998;102:149-63.

47. Helenius M, Makelainen L, Salminen A. Attenuation of NF-kB signaling response to UVB light during cellular senescence. Exp Cell Res. 1999;248:194-202.

48. Huang MC, Liao JJ, Bonasera S, Longo DL, Goetzl EJ. Nuclear factor- $\mathrm{KB}$-dependent reversal of aging-induced alterations in $\mathrm{T}$ cell cytokines. FASEB J. 2008;22:2142-50.

49. Sinclair DA, Guarente L. Extrachromosomal rDNA circles-a cause of aging in yeast. Cell. 1997;91:1033-42.

50. Kaeberlein M, McVey M, Guarente L. The SIR2/3/4 complex and SIR2 alone promote longevity in Saccharomyces cerevisiae by two different mechanisms. Genes Dev. 1999;13:2570-80.

51. Michan S, Sinclair D. Sirtuins in mammals: insights into their biological function. Biochem J. 2007;404:1-13.

52. Guarente L. Sirtuins as potential targets for metabolic syndrome. Nature. 2006;444:868-74

53. Longo VD, Kennedy BK. Sirtuins in aging and age-related disease. Cell. 2006;126:257-68.

54. Kwon HS, Ott M. The ups and downs of SIRT1. Trends Biochem Sci. 2008;33:517-25.

55. Yeung F, Hoberg JE, Ramsey CS, Keller MD, Jones DR, Frye RA, et al. Modulation of NF-kB-dependent transcription and cell survival by the SIRT1 deacetylase. EMBO J. 2004;23:2369-80.
56. Yang SR, Wright J, Bauter M, Seweryniak K, Kode A, Rahman I. Sirtuin regulates cigarette smoke-induced proinflammatory mediator release via RelA/p65 NF-kappaB in macrophages in vitro and in rat lungs in vivo: implications for chronic inflammation and aging. Am J Physiol Lung Cell Mol Physiol. 2007;292:L567-76.

57. Kwon HS, Brent MM, Getachew R, Jayakumar P, Chen LF, Schnolzer M, et al. Human immunodeficiency virus type 1 Tat protein inhibits the SIRT1 deacetylase and induces T cell hyperactivation. Cell Host Microbe. 2008;3:158-67.

58. Lombard DB, Schwer B, Alt FW, Mostoslavsky R. SIRT6 in DNA repair, metabolism and ageing. J Intern Med. 2008;263:128-41.

59. Mostoslavsky R, Chua KF, Lombard DB, Pang WW, Fischer MR, Gellon L, et al. Genomic instability and aging-like phenotype in the absence of mammalian SIRT6. Cell. 2006;124:315-29.

60. Kawahara TLA, Michishita E, Adler AS, Damian M, Berber E, Lin M, et al. SIRT6 links histone H3 lysine 9 deacetylation to NF$\kappa \mathrm{B}-$ dependent gene expression and organismal life span. Cell. 2009;136:62-74.

61. Braeckman B, Vanfleteren JR. Genetic control of longevity in $C$. elegans. Exp Gerontol. 2007;42:90-8.

62. Burnell AM, Houthoofd K, O'Hanlon K, Vanfleteren JR. Alternate metabolism during the dauer stage of the nematode Caenorhabditis elegans. Exp Gerontol. 2005;40:850-6.

63. Greer EL, Brunet A. FOXO transcription factors at the interface between longevity and tumor suppression. Oncogene. 2005;24:7410-25.

64. Coffer PJ, Burgering BMT. Forkhead-box transcription factors and their role in the immune system. Nat Rev Immunol. 2004;4:889-99.

65. Peng SL. Foxo in the immune system. Oncogene. 2008;27:2337-44.

66. Lin L, Hron JD, Peng SL. Regulation of NF-kappaB, Th activation, and autoinflammation by the forkhead transcription factor Foxo3a. Immunity. 2004;21:203-13.

67. Lee HY, Youn SW, Kim JY, Park KW, Hwang CI, Park WY, et al. FOXO3a turns the tumor necrosis factor receptor signaling towards apoptosis through reciprocal regulation of c-Jun Nterminal kinase and NF-kB. Arterioscler Thromb Vasc Biol. 2008;28:112-20.

68. Berdichevsky A, Viswanathan M, Horvitz HR, Guarente L. C. elegans SIR-2.1 interacts with 14-3-3 proteins to activate DAF-16 and extend life span. Cell. 2006;125:1165-77.

69. Salminen A, Ojala J, Huuskonen J, Kauppinen A, Suuronen T, Kaarniranta $\mathrm{K}$. Interaction of aging-associated signaling cascades: inhibition of NF-KB signaling by longevity factors FoxOs and SIRT1. Cell Mol Life Sci. 2008;65:1049-58.

70. Belvin MP, Anderson KV. A conserved signaling pathway: the Drosophila Toll-Dorsal pathway. Annu Rev Cell Dev Biol. 1996;12:393-416.

71. Gauldie J. Inflammation and the aging process: devil or angel. Nutr Rev. 2007;65:S167-9.

72. Libby P. Inflammatory mechanisms: the molecular basis of inflammation and disease. Nutr Rev. 2007;65:S140-6.

73. Argiles JM, Busquets S, Felipe A, Lopez-Soriano FJ. Molecular mechanisms involved in muscle wasting in cancer and ageing: cachexia versus sarcopenia. Int $\mathrm{J}$ Biochem Cell Biol. 2005;37:1084-104.

74. Delano MJ, Moldawer LL. The origins of cachexia in acute and chronic inflammatory diseases. Nutr Clin Pract. 2006;21:68-81.

75. Li H, Malhotra S, Kumar A. Nuclear factor- $\mathrm{kB}$ signaling in skeletal muscle atrophy. J Mol Med. 2008;86:1113-26.

76. Cai D, Frantz JD, Tawa NE Jr, Melendez PA, Oh BC, Lidov $\mathrm{HGW}$, et al. IKKß/NF- $\mathrm{KB}$ activation causes severe muscle wasting in mice. Cell. 2004;119:285-98.

77. Sandri M, Sandri C, Gilbert A, Skurk C, Calabria E, Picard A, et al. Foxo transcription factors induce the atrophy-related ubiquitin ligase atrogin-1 and cause skeletal muscle atrophy. Cell. 2004;117:399-412. 
78. Wang E. Regulation of apoptosis resistance and ontogeny of agedependent diseases. Exp Geront. 1997;32:471-84.

79. Warner HR. Is cell death and replacement a factor in aging? Mech Age Dev. 2007;128:13-6.

80. Salminen A, Kaarniranta K. Regulation of the aging process by autophagy. Trends Mol Med. 2009 doi:10.1016/j.molmed.2009. 03.004

81. Cuervo AM. Autophagy and aging: keeping that old broom working. Trends Genet. 2008;24:604-12.

82. Dutta J, Fan Y, Gupta N, Fan G, Gelinas C. Current insights into the regulation of programmed cell death by NF- $\mathrm{BB}$. Oncogene. 2006;25:6800-16

83. Papa S, Zazzeroni F, Pham CG, Bubici C, Franzoso G. Linking JNK signaling to NF-kappaB: a key to survival. J Cell Sci. 2004;117: 5197-208.

84. Terman A, Brunk UT. Oxidative stress, accumulation of biological "garbage", and aging. Antioxid Redox Signal. 2006;8:197-204.

85. Bergamini E, Cavallini G, Donati A, Gori Z. The role of autophagy in aging: its essential part in the anti-aging mechanism of caloric restriction. Ann NY Acad Sci. 2007;1114:69-78.

86. Dan HC, Baldwin AS. Differential involvement of IкB kinases $\alpha$ and $\beta$ in cytokine- and insulin-induced mammalian target of rapamycin activation determined by Akt. J Immunol. 2008;180:7582-9.

87. Lee DF, Kuo HP, Chen CT, Hsu JM, Chou CK, Wei Y, et al. IKKß suppression of TSC1 links inflammation and tumor angiogenesis via the mTOR pathway. Cell. 2007;130:440-55.

88. Lee IH, Cao L, Mostoslavsky R, Lombard DB, Liu J, Bruns NE, et al. A role for the NAD-dependent deacetylase Sirt1 in the regulation of autophagy. Proc Natl Acad Sci USA. 2008; 105:3374-9.

89. Salminen A, Lehtonen M, Suuronen T, Kaarniranta K, Huuskonen J. Terpenoids: natural inhibitors of NF- $\mathrm{KB}$ signaling with antiinflammatory and anticancer potential. Cell Mol Life Sci. 2008;65:2979-99.

90. Bremner P, Heinrich M. Natural products as targeted modulators of the nuclear factor-kappaB pathway. J Pharm Pharmacol. 2002;54:453-72.

91. Rahman I, Biswas SK, Kirkham PA. Regulation of inflammation and redox signaling by dietary polyphenols. Biochem Pharmacol. 2006;72:1439-52.

92. Mattson MP, Cheng A. Neurohormetic phytochemicals: low-dose toxins that induce adaptive neuronal stress responses. Trends Neurosci. 2006;29:632-9.

93. Rattan SI. Hormesis in aging. Ageing Res Rev. 2008;7:63-78.

94. Shakibaei M, Harikumar KB, Aggarwal BB. Resveratrol addiction: to die or not to die. Mol Nutr Food Res. 2009;53:115-28.

95. Keifer JA, Guttridge DC, Ashburner BP, Baldwin AS Jr. Inhibition of NF- $\mathrm{KB}$ activity by thalidomide through suppression of IkB kinase activity. J Biol Chem. 2001;276:22382-7.

96. Bordone L, Guarente L. Calorie restriction, SIRT1 and metabolism: understanding longevity. Nat Rev Mol Cell Biol. 2005;6:298-305.

97. Morgan TE, Wong AM, Finch CE. Anti-inflammatory mechanisms of dietary restriction in slowing aging processes. Interdiscip Top Gerontol. 2007;35:83-97.

98. Weindruch R, Kayo T, Lee CK, Prolla TA. Microarray profiling of gene expression in aging and its alteration by caloric restriction in mice. J Nutr. 2001;131:918S-23S. 